Technical Paper

\title{
Compression-grinding Treatment of Wet Rice Straw for Bioethanol Production
}

\author{
Fumio HaSegAWA, Kiyotaka SAGA, Yutaka KaIZU, and Kenji IMOU
}

(Received December 24, 2013)

\begin{abstract}
We have developed a novel rice straw collection system that incorporates compression-grinding method combined with lime treatment for use on rice farms. In this study, we determined the improvement in sugar yield by enzymatic saccharification and in resistance to biological decomposition by processing wet rice straw by using the proposed treatment method. Our proposed pretreatment method for rice straw successfully improved the sugar yield and resistance to biological decomposition. Pretreatment of rice straw by compression grinding combined with lime treatment can be conducted on the farm itself, immediately after harvest. Thus, incorporation of this method for the rice straw collection in bioethanol production may allow for the skipping of conventional drying step on farms and other pretreatment process performed for enzymatic saccharification in plants and for the effective utilization of previously abandoned difficult-to-dry wet biomass as feedstock in bioethanol production. Skipping of these steps would reduce the cost of ethanol production.
\end{abstract}

\section{Key Words}

Bioethanol, Rice straw, Lime treatment, Compression grinding, Enzymatic saccharification

\section{Introduction}

Rice straw is rich in carbohydrates and can be potentially used for ethanol production in Japan ${ }^{11}$. However, immediately after harvest the moisture content in rice straw is as high as $50 \%$ on wet basis (w.b.). To prevent biological decomposition, rice straws are dried to a moisture content of $15 \%$ w.b. in farms, after harvest by turning over once or twice to speed up the process. However, sunny weather for several consecutive days is required in this method, after which the dried rice straws are collected as a roll bale. This collection system is costly, which is major obstacle in adoption of this system for commercial bioethanol production from rice straw in Japan ${ }^{2)}$. Furthermore, in some regions, especially in Hokkaido and Japan Sea side area of the Tohoku region, the weather conditions are unfavorable for sufficient drying of the rice straw in order to prevent its biological decomposition.

Another problem is high resistance of rice straw to enzymatic saccharification, similar to that observed in other lignocellulosic biomass ${ }^{3}$. Several pretreatment approaches to

Graduate School of Agricultural and Life Sciences,

The University of Tokyo

1-1-1, Yayoi, Bunkyo-ku, Tokyo 113-8657, Japan facilitate enzymatic saccharification of lignocellulosic biomass have been proposed in the literature such as acidic, alkaline, and hydrothermal pretreatments, and ball milling ${ }^{3) ~}$ 5). Among these, the alkaline pretreatment with lime $\left[\mathrm{Ca}(\mathrm{OH})_{2}\right]$ has some advantages over other pretreatment methods. The effectiveness of mild lime pretreatment has been reported for herbaceous biomass ${ }^{5)}{ }^{6)}$. In addition, this pretreatment method can increase the efficiency of enzymatic saccharification even at room temperature ${ }^{7)}$ 8). Furthermore, as compared to other alkalis such as sodium hydroxide and ammonia, lime is a relatively low-cost and safe reagent ${ }^{91}{ }^{10)}$.

We have developed a novel system for the collection and pretreatment of rice straw, which involves compression grinding combined with lime treatment and can be conducted on the farm itself (Fig. 1). This approach involves simultaneous crushing and lime pretreatment for enzymatic saccharification, and the lime pretreatment can be performed without water addition, because wet rice straw contains sufficient moisture ${ }^{7)}$. Therefore, some pretreatment process steps performed in ethanol production plant can be omitted. High pH of lime-treated rice straw may prevent its biological decomposition, which allows skipping of the drying step as well as use of wet biomass 
a) Conventional rice straw collection system

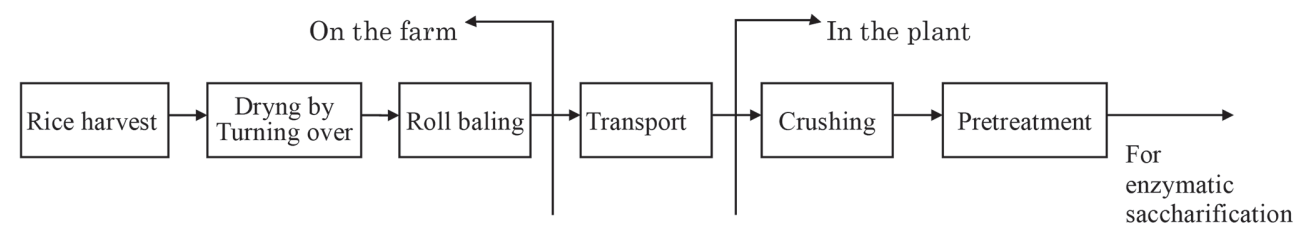

b) Rice straw collection system incorporating the compression-grinding treatment step

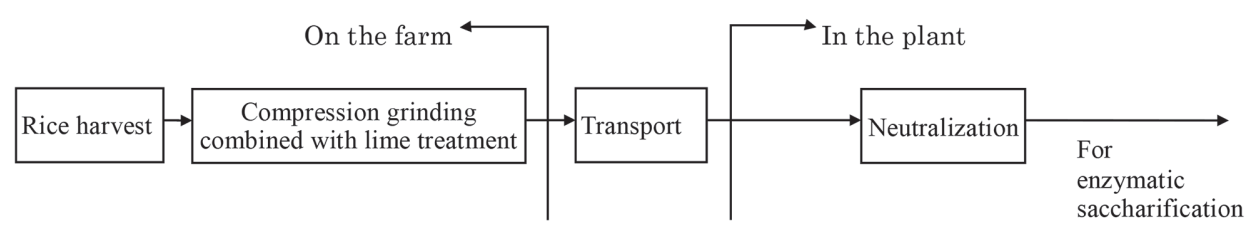

Fig. 1 Rice straw collection system for bioethanol production

previously abandoned due to insufficient drying. Thereby, the cost of ethanol production using rice straw as biomass can be reduced by installing the proposed collection system. In this study, we evaluated the sugar yield by enzymatic saccharification and resistance to biological decomposition by processing wet rice straw immediately after harvest by using the proposed treatment method to validate the abovementioned advantages of this method.

\section{Materials and Method}

\subsection{Materials}

Koshihikari and Aichinokaori rice straws were collected immediately after rice harvest from Minami-Boso city, Chiba, Japan in August 2013 and from Oguchi town, Aichi, Japan in October 2013. Rice straw was crushed with cutter mill equipped with a 1-cm screen and then stored at $4{ }^{\circ} \mathrm{C}$. The water content of the crushed rice straw was $54.3 \%$ w.b. and $62.1 \%$ w.b. for Koshihikari and Aichinokaori samples, respectively, as determined by using Moisture Analyzer MX-50 (A\&D Co., Ltd., Tokyo, Japan). The glucan and xylan content of the samples were analyzed by the method recommended by National Renewable Energy Laboratory (NREL) ${ }^{11)}$ Briefly, $0.3 \mathrm{~mL}$ of $72 \%$ sulfuric acid $\left(\mathrm{H}_{2} \mathrm{SO}_{4}\right)$ was added to approximately $30 \mathrm{mg}$ of rice straw and the mixture was incubated at $30^{\circ} \mathrm{C}$ for $1 \mathrm{~h}$. Next, the mixture was hydrolyzed with $8.4 \mathrm{~mL}$ of water at $121^{\circ} \mathrm{C}$ for $1 \mathrm{~h}$. The hydrolysate was neutralized with calcium carbonate $\left(\mathrm{CaCO}_{3}\right)$ and analyzed by high-performance liquid chromatography (HPLC). The glucan and xylan concentrations in one gram of rice straw was $358 \mathrm{mg}$ and $168 \mathrm{mg}$, respectively, in Koshihikari straw and $347 \mathrm{mg}$ and 172 mg, respectively, in Aichinokaori straw.

\subsection{Compression grinding combined with lime treatment}

One-axis extruder (Shokusenki SM-05-1.5;
Shinkozoki, Ogaki, Japan) was used as a compressiongrinding device (Fig. 2, Fig. 3). The processed material was pushed ahead by a screw and grinded between the screw and the inner surface. Before extruding from the discharge holes on the die, the material was compressed by rotation of the screw and cut by a cutter. The clearance between the screw and the inner surface is $2 \mathrm{~mm}$. The screw rotates at $150 \mathrm{rpm}$ and processing speed is $10-20 \mathrm{~kg} / \mathrm{h}$. Lime (Wako Pure Chemicals, Japan) was added to the crushed rice straw in a $45-\mathrm{L}$ plastic bag and mixed until the samples turned yellowish
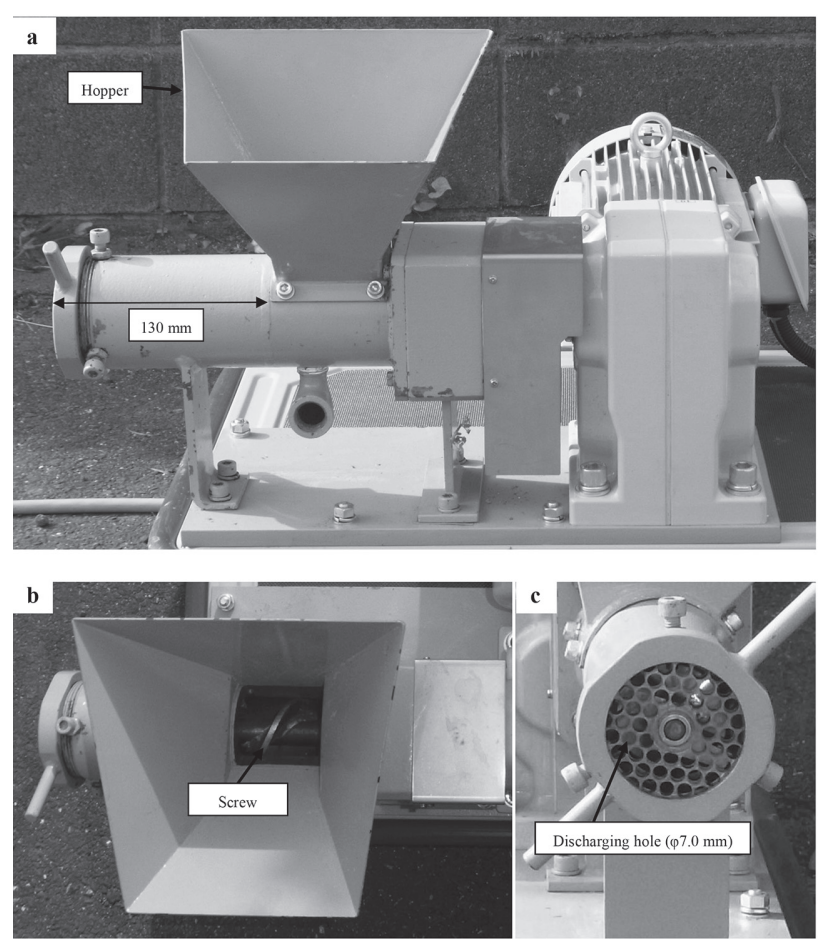

Fig. 2 The one-axis extruder (Shokusenki SM-05-1.5; Shinkozoki, Ogaki, Japan) used in this study; a: side view, b: top view, c: front view 


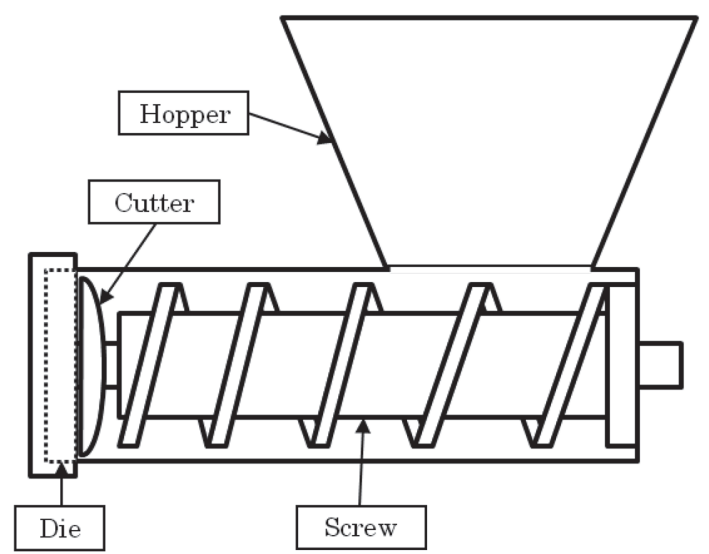

Fig. 3 Structure of the one-axis extruder

and then the samples were subjected to compression grinding within a few hours. Approximately $5 \mathrm{~kg}$ of samples was used for a series of compression-grinding treatment. The samples were fed to the hopper by hand. Some of the samples were treated once, while some were treated five times. The samples were well mixed after each treatment and refed to the hopper. The pretreated samples were stored in a zippered bag at room temperature and examined for biological decomposition. Table 1 shows the conditions of compression-grinding treatment. The first 4 samples [K0Cl was used as control (no lime supplement)] were used for examining the effect of compression grinding, and the last 5 samples were used for examining the effect of lime supplementation.

\subsection{Enzymatic saccharification}

Enzymatic saccharification was performed with Celluclast 1.5 L as cellulase (Sigma-Aldrich Japan K.K., Chiba, Japan), Novozyme 188 as $\beta$-glucosidase (SigmaAldrich Japan K.K.), and Optimash BG as hemicellulase (Danisco Japan Ltd., Tokyo, Japan). The rice straw samples one week after the compression-grinding treatment was used for enzymatic saccharification tests. The pretreated samples containing $100 \mathrm{mg}$ of cellulose, $8.7 \mathrm{~mL}$ of water, and $1.0 \mathrm{~mL}$ of $0.5 \mathrm{M}$ acetate buffer $(\mathrm{pH} 4.5)$ were mixed in a $25-\mathrm{mL}$ bottle. $10 \% \mathrm{H}_{2} \mathrm{SO}_{4}$ was used to adjust the $\mathrm{pH}$ to 5. Then, the enzyme cocktail (Celluclast 1.5L, $10 \mathrm{mg}$ protein/g glucan; Novozyme 188, $10 \mathrm{mg}$ protein/g glucan; Optimash BG, $100 \mu \mathrm{L} / \mathrm{g}$ glucan), tetracycline $(60 \mu \mathrm{g} / \mathrm{mL}$, final concentration), and cyclohexamide $(80 \mu \mathrm{g} / \mathrm{mL}$, final concentration) were added to the sample, and the reaction mixture was incubated at $37^{\circ} \mathrm{C}$ for $72 \mathrm{~h}$. The glucose and xylose concentrations were determined by HPLC, and the recovery rate was estimated based on the total amount of glucose and xylose in the samples before compressiongrinding treatment.

\subsection{Sugar analysis}

Sugar concentration was determined using a Shimadzu LC-20 HPLC system (Shimadzu Co., Ltd., Kyoto, Japan) equipped with the Sugar SP0810 column (Shoko Co., Ltd., Tokyo, Japan) and a refractive index detector, RID-10A (Shimadzu). The mobile phase was $\mathrm{H}_{2} \mathrm{O}$, applied at a flow rate of $1.0 \mathrm{~mL} / \mathrm{min}$, and the column temperature was set at $80^{\circ} \mathrm{C}$.

\section{Results and Discussion}

Table 2 shows the moisture content of rice straw samples one week after compression-grinding treatment and the amount of $10 \% \mathrm{H}_{2} \mathrm{SO}_{4}$ used for the $\mathrm{pH}$ adjustment. The moisture content of each sample was almost the same as that before treatment.

Fig. 4 shows the results of the enzymatic saccharification of rice straw samples treated by compression grinding for different periods. The compressiongrinding treatment enhanced the sugar recovery rate as compared to lime treatment without compression grinding at $90^{\circ} \mathrm{C}$ for $2 \mathrm{~h}$. The temperature of the die of the extruder rose $>90^{\circ} \mathrm{C}$ in a few minutes and kept during the treatment. During compression grinding, the rice straw samples were not only heated to $>90^{\circ} \mathrm{C}$ by friction and shearing, but also exposed to high pressure. Small water

Table 1 Conditions of compression-grinding treatment

\begin{tabular}{l|l|c|l}
\hline & Rice straw & Lime $(\mathrm{g} / \mathrm{kg}$-rice straw) & \multicolumn{1}{c}{ Treatment } \\
\hline K0C1 & Koshihikari & 0 & Compression grinding once \\
\hline K10C0 & Koshihikari & 100 & Incubation at $90^{\circ} \mathrm{C}$ for 2 hours \\
\hline K10C1 & Koshihikari & 100 & Compression grinding once \\
\hline K10C5 & Koshihikari & 100 & Compression grinding five times \\
\hline A0C1 & Aichinokaori & 0 & Compression grinding once \\
\hline A5C1 & Aichinokaori & 50 & Compression grinding once \\
\hline A5C5 & Aichinokaori & 50 & Compression grinding five times \\
\hline A10C1 & Aichinokaori & 100 & Compression grinding once \\
\hline A10C5 & Aichinokaori & 100 & Compression grinding five times \\
\hline
\end{tabular}


Table 2 Moisture content of the samples one week after compression-grinding treatment and the amount of $10 \%$ $\mathrm{H}_{2} \mathrm{SO}_{4}$ used for $\mathrm{pH}$ adjustment

\begin{tabular}{l|c|l}
\hline & $\begin{array}{l}\text { Moisture content one week } \\
\text { after compression-grinding } \\
\text { treatment (\%) }\end{array}$ & $\begin{array}{l}\text { Amount of } 10 \% \mathrm{H}_{2} \mathrm{SO}_{4} \\
\text { used for } \mathrm{pH} \text { adjustment } \\
(\mathrm{mL})\end{array}$ \\
\hline $\mathrm{K} 10 \mathrm{C} 0$ & 53.5 & 0.18 \\
\hline $\mathrm{K} 10 \mathrm{C} 1$ & 49.5 & 0.18 \\
\hline $\mathrm{K} 10 \mathrm{C} 5$ & 47.0 & 0.18 \\
\hline $\mathrm{A} 5 \mathrm{C} 1$ & 58.3 & 0.04 \\
\hline $\mathrm{A} 5 \mathrm{C} 5$ & 56.1 & 0.06 \\
\hline $\mathrm{A} 10 \mathrm{C} 1$ & 60.1 & 0.20 \\
\hline $\mathrm{A} 10 \mathrm{C} 5$ & 56.0 & 0.19 \\
\hline
\end{tabular}

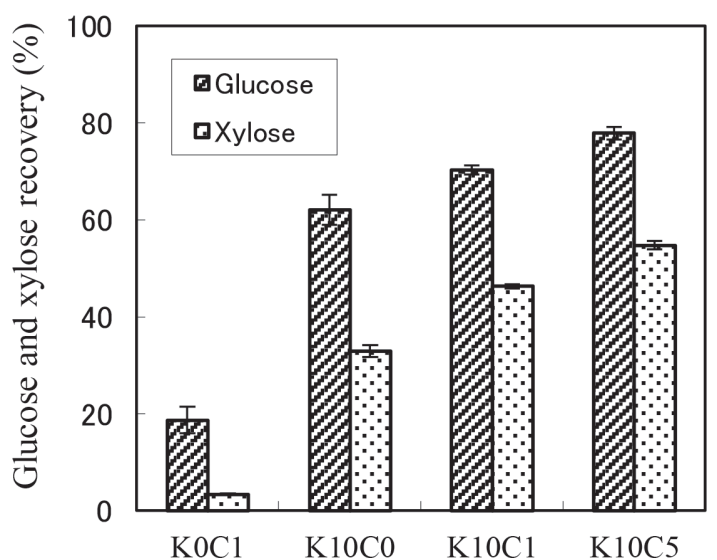

Fig. 4 The glucose and xylose recovery rate from rice straw (Koshihikari) subjected to compression grinding for different time periods after enzymatic saccharification for 72 h. KOC1 represents Koshihikari rice straw subjected compression grinding once without lime supplement. K10C0 represents Koshihikari rice straw subjected to $10 \%$ lime treatment at $90{ }^{\circ} \mathrm{C}$ for $2 \mathrm{~h}$ without compression grinding. $\mathrm{K} 10 \mathrm{C} 1$ and $\mathrm{K} 10 \mathrm{C} 5$ represent Koshihikari rice straw subjected to compression grinding for one and five times, respectively, with 10\% lime traetment.

bubbles were observed, whether lime was supplemented or not, on the surface of the treated rice straw samples extruded from discharge hole, which indicate that during compression grinding, water present in the pressed rice straw samples was extruded under high pressure condition and dissolved lime. After the release from the discharging hole, the water soaked into the rice straw samples again. Thus, high pressure condition during compression-grinding treatment enable the water in the rice straw samples to be effectively used in lime treatment for improved sugar recovery rate. Generally, lime treatment is performed under the conditions of high water content $(>80 \%)^{5)}{ }^{6)}$. For instance, Park et al. ${ }^{6)}$ reported that the glucose and xylose yields from rice straw sample treated at $121^{\circ} \mathrm{C}$ for $1 \mathrm{~h}$ in the presence of $0.2 \mathrm{~g} / \mathrm{g}$-rice straw of lime and $50 \mathrm{~g} / \mathrm{L}$ substrate were $75 \%$ and $66 \%$, respectively. In our study, the lime treatment of samples with lower water content $(54.3 \%$ and $62.1 \%)$ improved the enzymatic digestibility of rice straw similar to that by lime treatment in the presence of excess water. Compression grinding combined with lime treatment did not require additional water because of the presence of sufficient water originally contained in the wet rice straw samples just after rice harvest. Five consequent treatments resulted in the highest sugar yield after enzymatic saccharification, suggesting that processing one time by using a larger compression-grinding device, which provides longer processing time when samples are grinded under high temperature and pressure condition, can increase the sugar yield to an extent similar to that obtained by repeated treatments.

Compression grinding combined with lower lime concentration (5\%: $50 \mathrm{~g} / \mathrm{kg}$-dry rice straw) was also performed. Fig. 5 shows the result of enzymatic saccharification of rice straw samples treated with different lime concentrations. Sugar yield from $5 \%$ lime-treated samples was lower than that from 10\% lime treated ones; this finding is consistent with those reported earlier ${ }^{5)}$ 6). These results indicate that compression-grinding treatment requires at least $10 \%$ lime for efficient sugar recovery rate which is similar to the concentration used for treatment of rice straw with high water content.

Biological decomposition such as contamination with molds was observed in the samples compression-

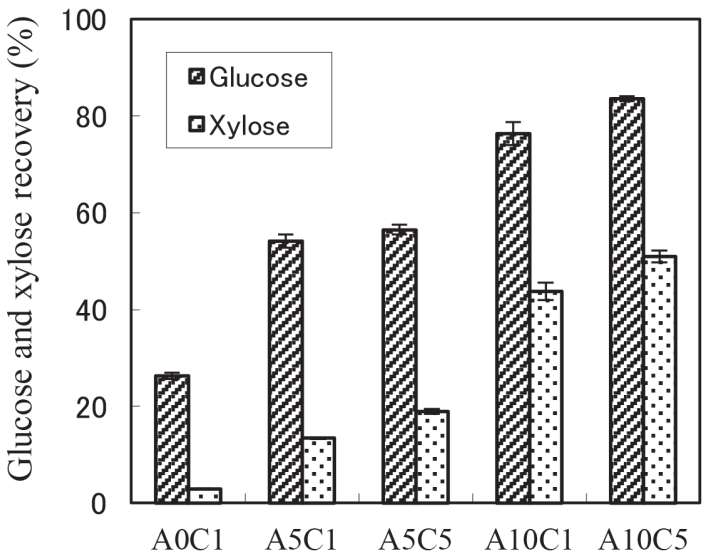

Fig. 5 The glucose and xylose recovery rate from rice straw (Aichinokaori) treated with different lime concentrations, after enzymatic saccharification for $72 \mathrm{~h}$. A0C1 represents Aichinokaori rice straw subjected to compression grinding once without lime treatment. A5C1 and A5C5 represent Aichinokaori rice straw subjected to compression grinding for one and five times, respectively, with $5 \%$ lime treatment. A10C1 and A10C5 represent Aichinokaori rice straw subjected to compression grinding for one and five times, respectively, with $10 \%$ lime treatment. 
grinded without lime and in the 5\% lime-treated samples 1 week after treatment, but no biological decomposition was noted in the $10 \%$ lime-treated samples up to 3 months after treatment. In addition, high glucose recovery rate of $10 \%$-lime-treated samples in enzymatic saccharification tests also indicates resistance to biological decomposition. $10 \%$ lime supplement was found to prevent biological decomposition of rice straw with high water content immediately after rice harvest.

In this study, rice straw samples after compressiongrinding treatment were discharged partly in the shape of pellet (Fig. 6). Ohnishi et al. ${ }^{12)}$ examined the condition that results in shaping of wet rice straw into a pellet form by one-axis extruder and found that the sample moisture content and the shape of the discharging hole on the die are important factors that determine the shape. Thus, the rate of sample shaping into a pellet-like form after compressiongrinding treatment can be improved by changing the shape of the discharging hole of compression-grinding device, such as chamfering the inner side of discharging holes. Rice straw shaped into pellet had high density, which can skip the treatment for size reduction to increase the transportation efficiency. Thereby, the collection and transportation of rice straw can be further simplified.

Because the compression-grinding device connected with tractor by power take-off (PTO) shaft has been already commercialized, the compression grinding combined with lime treatment can be performed on the farms with small modifications in the device such as attaching a lime feeder and changing the discharging hole. Fig. 1b depicts our proposed rice straw collection system for bioethanol production, which does not require any prior straw drying. Pretreatment for enzymatic saccharification was also performed during rice straw collection. Incorporation of

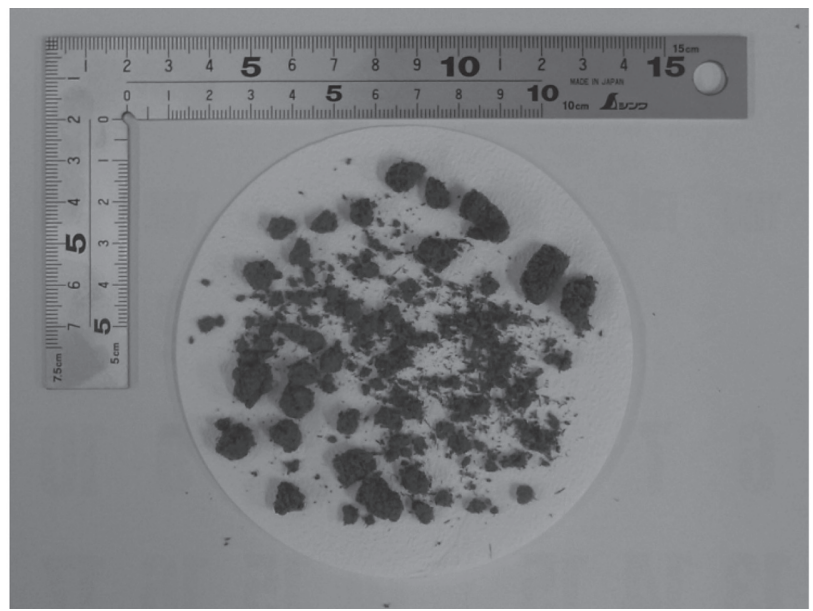

Fig. 6 Rice straw subjected to five-times compression grinding by one-axis extruder combined with $10 \%$ lime treatment proposed compression-grinding treatment can reduce the cost of the ethanol production by avoiding the drying step on farms and some of pretreatment steps in the plant as well as facilitate use of wet biomass previously abandoned because of insufficient drying.

\section{Conclusion}

This study proposes a novel compression-grinding method combined with lime treatment as an effective method for the pretreatment of rice straw with the aim to increase the sugar yield by enzymatic saccharification and to increase resistance to biological decomposition. The glucose and xylose recovery rate of the rice straw sample treated in optimum condition were $84 \%$ and $51 \%$, respectively, compared to $26 \%$ and $3 \%$ of non-treated sample. No biological decomposition was noted in the $10 \%$ lime-treated samples up to 3 months after treatment. Compression grinding combined with lime treatment can be performed on farms immediately after harvesting the rice. Thus, incorporation of this method into current rice straw collection system for bioethanol production would allow skipping of the conventional drying step and some of pretreatment steps in the plant and make use of the previously abandoned wet biomass as feedstock, which can reduce the overall cost of ethanol production from rice straw.

\section{References}

1) Matsumura, Y.; Minowa, T.; Yamamoto, H., Biomass Bioenergy, 29, 347-354 (2005)

2) Saga, K.; Imou, K.; Yokoyama, S.; Fujimoto, S.; Yanagida, T.; Minowa, T., Energy and Resouces, 29, 8-13 (2008)

3) Sun, Y:; Cheng, J., Bioresour. Technol., 83, 1-11 (2002)

4) Hideno, A.; Inoue, H.; Tukahara, K.; Fujimoto, S.; Minowa, T.; Inoue, S.; Endo, T.; Sawayama, S., Bioresour. Technol., 100, 2706-2711 (2009)

5) Cheng, Y.; Zheng, Y.; Yu, C. W.; Dooley, T. M.; Jenkins B. M.; VanderGheynst, J. S., Appl. Biochem. Biotechnol., 162 1768-1784 (2010)

6) Park, J.; Shiroma, R.; Al-Haq, M. I.; Zhang, Y.; Ike, M.; Arai-Sanoh, Y.; Ida, A.; Kondo, M.; Tokuyasu, K., Bioresour. Technol., 101, 6805-6811 (2010)

7) Digman, M. F.; Shinners, K. J.; Casler, M. D.; Dien, B. S.; Hatfield, R. D.; Jung, H. J. G.; Muck, R. E.; Weimer, P. J., Bioresour. Technol., 101, 5305-5314 (2010)

8) Shiroma, R.; Park, J.; Al-Haq, M. I.; Arakane, M.; Ike, M.; Tokuyasu, K., Bioresour. Technol., 102, $2943-2949$ (2011)

9) Kaar, W. E.; Holtzapple, M. T., Biomass Bioenergy, 18, 189-199 (2000)

10) Saha, B. C.; Cotta M. A., Biomass Bioenergy, 32, 971-977 
(2008)

11) National renewable Energy Laboratory (NREL), http:// www.nrel.gov/docs/gen/fy13/42618.pdf (Last access
2013.12.19)

12) Ohnishi, M.; Fujii, Y.; Nagasawa, N.; Nguyen, K. Q.; Teshima, T., JSAM, 75, 167-174 (2013) 